\title{
A phase 1 trial of imatinib, bevacizumab, and metronomic cyclophosphamide in advanced colorectal cancer
}

\author{
R K Kelley ${ }^{1}$, J Hwang ${ }^{2}$, M J M Magbanua ${ }^{3}, \mathrm{LWatt}^{1}, \mathrm{~J} \mathrm{H} \mathrm{Beumer}^{4}$, S M Christner ${ }^{5}$, S Baruchel ${ }^{6}$, B Wu ${ }^{6}, \mathrm{~L} \mathrm{Fong}^{7}$, \\ B M Yeh ${ }^{8}$, A P Moore ${ }^{9}$, A H Ko ${ }^{10}$, W M Korn ${ }^{11}$, S Rajpal ${ }^{12}$, J W Park ${ }^{13}$, M A Tempero ${ }^{14}$, A P Venook ${ }^{10}$ \\ and E K Bergsland*,10
}

\begin{abstract}
${ }^{1}$ Department of Medicine, University of California, San Francisco, Helen Diller Family Comprehensive Cancer Center, 1600 Divisadero Street, Box 1700, San Francisco, CA 94143, USA; ${ }^{2}$ Biostatistics and Computational Biology Core, University of California, San Francisco, Helen Diller Family Comprehensive Cancer Center, Medical Sciences, S1143, San Francisco, CA 94143, USA; ${ }^{3}$ Department of Medicine, University of California, San Francisco, Helen Diller Family Comprehensive Cancer Center, 2340 Sutter Street, Room S471, San Francisco, CA 94143, USA; ${ }^{4}$ Department of Pharmaceutical Sciences, University of Pittsburgh, The Hillman Cancer Center Research Pavilion, Suite G.27D, 5117 Centre Avenue, Pittsburgh, PA 15213-1863, USA; ${ }^{5}$ Molecular Therapeutics/Drug Discovery Program, University of Pittsburgh, School of Pharmacy, The Hillman Cancer Center Research Pavilion, Suite G.27d, 5117 Centre Avenue, Pittsburgh, PA 15213-1863, USA; ${ }^{6}$ Department of Paediatrics, University of Toronto, The Hospital For Sick Children, 555 University Avenue, Toronto, Ontario, Canada; ${ }^{7}$ Department of Medicine, University of California, San Francisco, Helen Diller Family Comprehensive Cancer Center, 513 Parnassus Avenue, Box 0511, San Francisco, CA 94143, USA; ${ }^{8}$ Department of Radiology, University of California, San Francisco, Helen Diller Family Comprehensive Cancer Center, 505 Parnassus Avenue, San Francisco, CA 94143, USA; ${ }^{9}$ Department of Medicine, University of California, San Francisco, Helen Diller Family Comprehensive Cancer Center, 1600 Divisadero Street, Box 1770, San Francisco, CA 94143, USA; ${ }^{10}$ Department of Medicine, University of California, San Francisco, Helen Diller Family Comprehensive Cancer Center, 1600 Divisadero Street, Box 1705, San Francisco, CA 94143, USA; ${ }^{11}$ Department of Medicine, University of California, San Francisco, Helen Diller Family Comprehensive Cancer Center, 2340 Sutter Street, Box 1387, San Francisco, CA 94143, USA; ${ }^{12}$ Kaiser Permanente, 1200 El Camino Real, South San Francisco, CA 94080, USA; ${ }^{13}$ Department of Medicine, University of California, San Francisco, Helen Diller Family Comprehensive Cancer Center, 1600 Divisadero Street, Box 1710, San Francisco, CA 94143, USA and ${ }^{14}$ Department of Medicine, University of California, San Francisco, Pancreas Center, 1600 Divisadero Street, Box 1770, San Francisco, CA 94143, USA
\end{abstract}

Background: This phase 1 clinical trial was conducted to determine the safety, maximum-tolerated dose (MTD), and pharmacokinetics of imatinib, bevacizumab, and metronomic cyclophosphamide in patients with advanced colorectal cancer (CRC).

Methods: Patients with refractory stage IV CRC were treated with bevacizumab $5 \mathrm{mg} \mathrm{kg}^{-1}$ i.v. every 2 weeks (fixed dose) plus oral cyclophosphamide q.d. and imatinib q.d. or b.i.d. in 28-day cycles with $3+3$ dose escalation. Response was assessed every two cycles. Pharmacokinetics of imatinib and cyclophosphamide and circulating tumour, endothelial, and immune cell subsets were measured.

Results: Thirty-five patients were enrolled. Maximum-tolerated doses were cyclophosphamide 50 mg q.d., imatinib 400 mg q.d., and bevacizumab $5 \mathrm{mg} \mathrm{kg}^{-1}$ i.v. every 2 weeks. Dose-limiting toxicities (DLTs) included nausea/vomiting, neutropaenia, hyponatraemia, fistula, and haematuria. The DLT window required expansion to 42 days (1.5 cycles) to capture delayed toxicities. Imatinib exposure increased insignificantly after adding cyclophosphamide. Seven patients (20\%) experienced stable disease for $>6$ months. Circulating tumour, endothelial, or immune cells were not associated with progression-free survival.

Conclusion: The combination of metronomic cyclophosphamide, imatinib, and bevacizumab is safe and tolerable without significant drug interactions. A subset of patients experienced prolonged stable disease independent of dose level.

*Correspondence: Professor EK Bergsland; E-mail: emilyb@medicine.ucsf.edu

Received 5 March 2013; revised 14 July 2013; accepted 19 August 2013; published online 10 September 2013

(c) 2013 Cancer Research UK. All rights reserved 0007-0920/13 
Colorectal cancer (CRC) is the second leading cause of cancer death in the United States (Jemal et al, 2010). Despite significant improvements in treatment options over the past decade, the median survival of patients with metastatic disease remains $<2$ years. Primary refractory disease, chemoresistance, and toxicity leave many fit patients without a standard treatment option at some point in their disease. New targets, treatments, and strategies in advanced CRC are urgently needed.

Fundamental to tumour progression, angiogenesis was validated as a therapeutic target in CRC with the demonstration that bevacizumab, a monoclonal antibody against the vascular endothelial growth factor (VEGF), increases response rate, delays progression, and prolongs survival when combined with standard chemotherapy (Folkman, 1971; Hurwitz et al, 2004). The continuation of bevacizumab in second-line therapy after progression also improves survival (Grothey et al, 2008; Bennouna et al, 2013). Other agents with anti-angiogenic activity show benefit after progression on bevacizumab-containing therapy, including regorafenib, a multikinase inhibitor that targets VEGF receptor signalling, and the novel decoy receptor fusion protein, aflibercept (VEGF-Trap) (Van Cutsem et al, 2012; Grothey et al, 2013). The precise mechanisms of action of bevacizumab, regorafenib, and aflibercept are poorly understood. In addition to impairing tumour angiogenesis, blockade of tumour-derived VEGF may modulate the host immune response against tumours by increasing the abundance of effector $\mathrm{T}$ cells and activated dendritic cells among tumour infiltrating immune cells. Conflicting evidence exists, however, with recent reports suggesting that VEGF inhibition may result in decreased anti-tumour immunity by blocking VEGFmediated innate immune cell recruitment to the tumour ( $\mathrm{Li}$ et al, 2006; Doloff and Waxman, 2012).

A different strategy to target tumour vasculature is the 'metronomic' administration of low-dose cytotoxic chemotherapy continuously over time, without scheduled breaks (Kerbel and Kamen, 2004). Metronomic chemotherapy is thought to preferentially target proliferating tumour-associated endothelial cells, impairing tumour angiogenesis and increasing apoptosis in vitro and in animal models (Bocci et al, 2002; Bertolini et al, 2003). Models of metronomic administration of cytotoxic agents suggest lower rates of toxicity and chemoresistance (Browder et al, 2000; Bertolini et al, 2003; Emmenegger et al, 2004). In patients with $\mathrm{CRC}$, metronomic administration of irinotecan was well tolerated and associated with disease stabilisation in a subset of patients who previously had progressed on standard schedules of irinotecan (Allegrini et al, 2008). Cyclophosphamide is the cytotoxic agent most widely studied across metronomic chemotherapy regimens (Penel et al, 2011). In addition to an anti-angiogenic effect on tumour vasculature, metronomic cyclophosphamide also may act by depleting CD4 + CD25+ regulatory $\mathrm{T}$ cells (Tregs), thereby reducing their suppressive effects on anti-tumour immune responses (Motoyoshi et al, 2006; Ghiringhelli et al, 2007; Penel et al, 2011). In a series of 12 patients with metastatic breast cancer treated with metronomic cyclophosphamide, there was a transient significant reduction in Tregs, associated with a sustained increase in breast tumourreactive $\mathrm{T}$ cells ( $\mathrm{Ge}$ et al, 2012).

The addition of anti-angiogenic agents to metronomic cyclophosphamide is synergistic in preclinical studies (Browder et al, 2000; Pietras and Hanahan, 2005; Blansfield et al, 2008; Penel et al, 2011). In a transgenic mouse model of pancreatic islet cell tumours, Pietras and Hanahan (2005) showed that the combination of metronomic cyclophosphamide combined with the multikinase inhibitors, imatinib and sunitinib, induced greater anti-tumour activity than any of the three agents alone or pairwise. Pericyte coverage of tumour blood vessels was reduced with the combination, leading to the hypothesis that inhibition of platelet-derived growth factor receptor- $\beta$ (PDGFR $\beta)$-mediated pericyte support may disrupt existing tumour vasculature and augment anti-angiogenic effects. Blansfield et al (2008) studied a combination of metronomic cyclophosphamide, lenalidomide (an immunomodulatory and anti-angiogenic agent), and sunitinib to target the tumour microenvironment in a xenograft model of colon cancer. The combination of all three agents showed significantly greater inhibition of tumour proliferation and angiogenesis, and increased apoptosis, compared with any of the agents alone.

Human studies of metronomic cyclophosphamide combined with anti-angiogenic agents have demonstrated clinical evidence of anti-tumour efficacy, although interpretation of these studies is generally limited by small sample sizes, lack of a control arm, and heterogeneity of tumour type, treatments, and end points (Penel et al, 2011). A phase 2 trial of 70 patients with recurrent ovarian cancer treated with the combination of bevacizumab plus metronomic cyclophosphamide showed a promising 6-month progression-free survival (PFS) of $56 \%$ and partial response rate of $24 \%$ (Garcia et al, 2008). Another study in 38 patients with refractory ovarian cancer showed a median PFS of 4.5 months but was notable for grade 3 and 4 events of intestinal fistula, hypertension, haematuria, and arterial thrombosis (SanchezMunoz et al, 2010). In a study of 46 patients with advanced breast cancer treated with metronomic cyclophosphamide and capecitabine along with bevacizumab, an overall response rate of $48 \%$ was observed with minimal toxicity (Dellapasqua et al, 2008).

Building upon the preclinical rationale for combining metronomic chemotherapy with an anti-VEGF agent plus a PDGFR $\beta$ antagonist (to inhibit pericyte-mediated endothelial cell survival cues), we conducted a phase 1 trial to determine the safety, tolerability, maximum-tolerated dose (MTD), and recommended phase 2 dose (RP2D) of the combination of metronomic cyclophosphamide, imatinib, and bevacizumab in patients with advanced solid tumours for which bevacizumab is an approved therapy. Because of the established role for bevacizumab in metastatic CRC, the study was conducted in a CRC cohort. Pharmacokinetic (PK) analyses and exploratory biomarker measurements were performed.

\section{PATIENTS AND METHODS}

Patient selection. Patients were recruited and treated at the University of California, San Francisco (UCSF) Helen Diller Family Comprehensive Cancer Center. Patients with metastatic, histologically confirmed, incurable solid tumours refractory to standard therapies or for which no standard therapy exists and the following characteristics were eligible: age $\geqslant 18$ years; Eastern Cooperative Oncology Group (ECOG) performance status 0 or 1; insurance approval for treatment with bevacizumab; measurable disease by Response Evaluation Criteria in Solid Tumours (RECIST 1.0) with evidence of progression clinically or radiographically at time of enrollment; $\geqslant 4$ weeks since completion of prior treatments; resolution of any prior toxicity to $\leqslant$ grade 1 by National Cancer Institute (NCI) Common Terminology Criteria for Adverse Events (CTCAE) version 3.0; adequate organ function. Patients with uncontrolled hypertension or cardiovascular disease, arterial thrombotic events within 12 months, central or cavitary lung tumours in proximity to a major vessel, haemoptysis, abdominal fistula, perforation, abscess, known brain metastasis, serious nonhealing wounds or fractures, or other significant comorbidities were excluded. Prior therapy with bevacizumab was permitted. Concomitant medications were reviewed and adjusted as needed to avoid interactions. The trial was approved by the UCSF Institutional Review Board and was conducted in accordance with the Declaration of Helsinki and Good Clinical Practice. 
Study design and endpoints. The study was an investigatorinitiated, open-label, single-arm, phase 1 clinical trial employing a standard $3+3$ dose-escalation design with a cycle length of 28 days. The primary end points were the safety and MTD of the combination of imatinib, metronomic cyclophosphamide, and bevacizumab in patients with advanced solid tumours. Secondary end points were the effects of cyclophosphamide on imatinib PK after single doses and at steady state, as well as response rate and PFS. Exploratory end points included enumeration of circulating tumour, endothelial, and immune cells at baseline, during therapy, and at study termination.

Treatment plan. The starting dose of cyclophosphamide was $25 \mathrm{mg}$ orally once daily, with escalation to a target dose of $50 \mathrm{mg}$ (Penel et al, 2011). Imatinib dosing started at $400 \mathrm{mg}$ daily, with escalation to a target dose of $400 \mathrm{mg}$ orally twice daily based upon evidence of dose-dependent efficacy in other diseases (Talpaz et al, 2002; Verweij et al, 2004; Zalcberg et al, 2005). For all dose levels (DLs), a standard i.v. dose of $5 \mathrm{mg} \mathrm{kg}^{-1}$ bevacizumab every other week was employed (Hurwitz et al, 2004), see Table 2. Patients were enrolled following a standard $3+3$ dose escalation protocol, starting at DL 0 . If one dose-limiting toxicity (DLT) occurred among the first three patients, then the cohort was expanded to six patients. If 0 out of 3 or 1 out of 6 patients experienced a DLT, then dose escalation proceeded with enrollment of three patients to the next DL. The maximum DL with no more than one DLT in at least six patients during the DLT window was designated as the MTD and the RP2D. After identification of the MTD, an expansion cohort of six patients was enrolled for PK. Intrapatient dose escalation was not permitted. Imatinib was supplied by Novartis Oncology. Bevacizumab and cyclophosphamide were obtained from commercial supplies. Dose modifications for toxicity were conducted individually for each drug according to attribution. Supportive care including anti-diarrheal medications, anti-emetic agents, management of hypertension, diuretics for oedema, and topical therapies was administered as needed. Treatment was continued until radiographic or clinical progression, unacceptable toxicity, or withdrawal of consent. Patients removed from study for symptomatic progression during the DLT window were replaced.

Assessment of safety and toxicity. Patients were assessed for adverse events (AEs) weekly during cycle 1 and every 2 weeks in subsequent cycles. AEs were characterised using NCI CTCAE version 3.0. Laboratory abnormalities were reported as $\mathrm{AE}$ if considered clinically significant by the treating investigator. At study initiation, the DLT window was 1 cycle (28 days). After 21 patients had been accrued, the DLT window was expanded to 42 days ( 1.5 cycles), based upon the mid-study observation that many patients required dose reduction for toxicity early in cycle 2 , as discussed below. The DLT definition included: grade 4 haematologic toxicity except for grade 4 neutropaenia without fever lasting $<7$ days; prolonged grade 3 thrombocytopaenia $\geqslant 7$ days; any grade $\geqslant 3$ non-haematologic toxicity despite optimal supportive care, excluding fatigue; any grade $\geqslant 2$ toxicity requiring dose modification or treatment delay $>2$ weeks during DLT window; or discontinuation of any of the study drugs due to toxicity.

Measurement of tumour response and PFS. Target and nontarget lesions were defined by RECIST version 1.0 (Therasse et al, 2000). Computerised tomography (CT) or magnetic resonance imaging (MRI) of target and non-target lesions was performed at baseline and after every two cycles ( 8 weeks \pm 7 days) on protocol therapy. PFS was calculated from the first dose of protocol therapy until date of removal from study for radiographic or clinical progression or death from any cause. Among patients who were removed from study for reasons other than progression or death, PFS was censored at date of last contact or study removal.
PK analysis of imatinib and cyclophosphamide. Bevacizumab was assumed not to interact with the other agents. Pharmacokinetics of imatinib and cyclophosphamide was performed in an expansion cohort of six patients at the MTD. Blood samples for imatinib PK were collected in heparinised tubes over $24 \mathrm{~h}$ during day 1 of cycle 1 (imatinib alone) and cycle 2 (at steady state for all drugs). Samples times were before treatment, and at $0.5,1,2,3,4$, 8 , and $24 \mathrm{~h}$ after the cycle 1 day 1 (C1D1) dose; and at the same times around the cycle 2 day 1 (C2D1) imatinib dose. Plasma was prepared by centrifugation and immediately frozen at $-20^{\circ} \mathrm{C}$. Plasma concentrations of imatinib and its active metabolite, CGP74588, were determined with a validated liquid chromatography-mass spectrometry (LC-MS) assay (Parise et al, 2003). Plasma PK parameters, including area under the concentration $v s$ time curve (AUC) of imatinib and its metabolite were extracted from the data by non-compartmental methods with PK Solutions 2.0 (Summit Research Services, Montrose, CO, USA). To assess any effect of bevacizumab and cyclophosphamide on imatinib pharmacokinetics, we compared the $\mathrm{AUC}_{0 \text {-inf }}$ on $\mathrm{C} 1 \mathrm{D} 1$ with the $\mathrm{AUC}_{0-24 \mathrm{~h}}$ on C2D1.

For cyclophosphamide PK, $5 \mathrm{ml}$ of whole venous blood was collected in an EDTA Vacutainer tube before cyclophosphamide treatment and at $0.5,1,2,3,4,8$, and $24 \mathrm{~h}$ after cyclophosphamide ingestion on C2D1. The blood samples were centrifuged at $4{ }^{\circ} \mathrm{C}$ at 2000 r.p.m. for $10 \mathrm{~min}$. Plasma samples were collected and frozen at $-80^{\circ} \mathrm{C}$ until analysis. Cyclophosphamide concentration was measured by LC-MS/MS) (Stempak et al, 2006). Estimates of PK parameters for cyclophosphamide, including AUC, $C_{\max }, T_{\max }, t_{1 / 2}$, the apparent oral clearance $(\mathrm{Cl} / \mathrm{F})$ and apparent oral volume of distribution $\left(V_{\mathrm{d}} / F\right)$ were derived from individual concentrationtime data sets by non-compartmental methods using the software package WinNonlin (version 5.3, Pharsight Corporation, St Louis, MO, USA).

Circulating tumour cell and circulating endothelial cell enumeration. Peripheral blood for circulating tumour cell (CTC)/ circulating endothelial cell (CEC) enumeration was obtained before the start of therapy (baseline), at weeks 2, 6, and 8, and at end of treatment. The number of CTCs in $7.5 \mathrm{ml}$ of blood was measured using the CellSearch system (Veridex LLC, Raritan, NJ, USA) (Cohen et al, 2008). Circulating tumour cells were defined as nucleated EpCAM-positive cells that stain positive for cytokeratin and negative for leukocyte common antigen, CD45 (Allard et al, 2004). Circulating endothelial cell was evaluated using a previously described flow cytometry assay (Garcia et al, 2007; Rugo et al, 2012). It was identified by 4-colour flow cytometry using an FACSCalibur Flow cytometer (BD Biosciences, San Jose, CA, USA). It was defined as nucleated, CD31 positive, CD34 positive, and CD45 negative. In addition, CEC-related subpopulations were also evaluated including CD146-positive cells and progenitor and activated CEC defined as CD133 positive and CD105 positive, respectively.

The CTC and CEC values at baseline and on treatment were explored for association with PFS and best response. Circulating tumour cell was tested for correlation at each time point using Spearman's test. Cox proportional hazard models were used for correlation with PFS. In the PFS models, CTC values were dichotomised into $(0,1)$ variables using the accepted cutoff of $\geqslant 3$ CTC/7.5 ml (Cohen et al, 2008). The CEC data were modelled using cell counts as continuous variables (log scale). Additional PFS models evaluated change from baseline for CTC and CEC as a dichotomous variable defined as increase or no increase at each time point.

Immune cells. In a subset of six patients enrolled before September 2008, peripheral blood mononuclear cells (PBMCs) were isolated from blood samples by Ficoll gradient separation. PBMC was cryopreserved at baseline and subsequent time points 
and assayed in parallel for each study subject. For phenotypic characterisation, cells were thawed and stained with antibodies to delineate CD4 and CD8 T cells. Tregs were identified by intracellular FoxP3 staining and enumerated by flow cytometry.

Statistical analysis. Safety and toxicity were assessed by clinical review of all relevant parameters including AEs, laboratory results, vital signs, and other clinical measurements. The AE toxicities were summarised by DL for all patients and by body system and grade. The adverse experiences were summarised as counts, frequencies, and grade at each DL. Descriptive statistics were used for safety, tumour responses, $\mathrm{PK}$, and other biomarker measurements. Between-day PK comparisons were performed with a two-tailed, Wilcoxon exact signed rank test, where $P<0.05$ was considered as significant. For efficacy assessment, response rate (stable disease or progressive disease) was estimated as counts and proportion. PFS was analysed using Kaplan-Meir methods to estimate the mean and median with 95\% confidence interval and descriptively summarised as appropriate by DL and by overall patients. Due to the cohort sample size, no formal statistical testing was performed for the safety or response results.

\section{RESULTS}

Patient characteristics. A total of 35 patients, all with a diagnosis of metastatic CRC, were enrolled on this study between August 2006 and June 2010. Baseline characteristics of the patients are shown in Table 1 . The study population was heavily treated with a median of three prior lines of therapy, and all patients (100\%) had failed prior 5-fluorouracil and/or capecitabine, oxaliplatin, irinotecan, and bevacizumab. Twenty-four of thirty-five (69\%) had received a monoclonal antibody targeting the epidermal growth factor receptor (EGFR). Tumour K-ras gene was mutant in 9 (26\%), wild type in $3(9 \%)$, and unknown in $23(66 \%)$, due to the fact that this study was initiated before the establishment of K-ras mutation as a biomarker for non-response to EGFR-targeted therapies in CRC. Accrual by DL is shown in Table 2.

Dose escalation, DLT, and MTD. DLTs were observed in all four DLs (Table 2). Initially designed with a DLT window of 28 days (1 cycle), 1 of 6 patients had a DLT of possibly related, grade 2 gastrointestinal fistula development at DL0, followed by 0 of 3 patients with DLT in both DL +1 and +2 . Three patients were subsequently enrolled to $\mathrm{DL}+3$. One patient was non-evaluable due to disease progression and was replaced. One patient had a DLT of grade 2 vomiting along with grade 3 hyponatraemia requiring dose reduction during the DLT window. This led to cohort expansion by three additional patients plus one replacement patient, without any DLTs. Two more patients then enrolled to $\mathrm{DL}+3$ into the planned 6-patient $\mathrm{PK}$ expansion cohort. At that point, it was noted that five of the nine patients enrolled to $\mathrm{DL}+3$ required dose reductions early in cycle 2 due to toxicity occurring shortly after the protocol-defined DLT window. Given concerns regarding poor tolerability with chronic therapy, the protocol was amended to expand the DLT window to 42 days ( 1.5 cycles). Under the revised DLT window, five of nine patients at DL +3 and one of three patients previously treated at $\mathrm{DL}+2$ were re-adjudicated as having had DLT events, so dosing was de-escalated to DL +2 . One of the two additional patients enrolled to $\mathrm{DL}+2$ experienced a DLT of grade 2 vomiting on day 18 , resulting in two of five patients at this DL with DLT and requiring de-escalation to DL +1 . The $\mathrm{DL}+1$ was expanded by four additional patients (as one of three original patients in this cohort had been removed for disease progression at 34 days, and thus was not evaluable for toxicity within the expanded 42-day DLT window). Among the six evaluable patients enrolled to $\mathrm{DL}+1$, one patient experienced a DLT of grade 2 nausea despite optimal supportive care requiring
Table 1. Baseline patient demographics and clinical characteristics

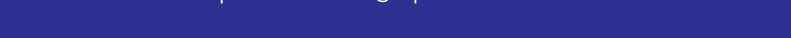

\begin{tabular}{|l|c|}
\hline Characteristic & Median (range, $\mathbf{N}=35)$ \\
\hline Age & $58(33-74)$ \\
\hline $\begin{array}{l}\text { Number prior lines of therapy for } \\
\text { metastatic disease }\end{array}$ & $3(2-6)$ \\
\hline Characteristic & Number of patients $(\%$, of $\mathbf{N}=35)$
\end{tabular}

\section{Gender}

\begin{tabular}{|l|r|}
\hline Male & $20(57)$ \\
Female & $15(43)$
\end{tabular}

\section{Race/ethnicity}

\begin{tabular}{|l|l|}
\hline White & $29(83)$
\end{tabular}

$\begin{array}{lr}\text { Black } & 2(6)\end{array}$

Asian

Hispanic

Other

Unknown

$0(0)$

1 (3)

$1(3)$

Cancer location

\begin{tabular}{|l|r|}
\hline Colon & $24(69)$ \\
Rectum & $11(31)$
\end{tabular}

ECOG score

0

1

$27(77)$

8 (23)

Prior systemic therapies

5-fluorouracil and/or capecitabine

$35(100)$

Oxaliplatin

Irinotecan

Bevacizumab

Cetuximab and/or panitumumab

Investigational agent(s)

35 (100)

35 (100)

35 (100)

24 (69)

4 (11)

Prior radiation and/or surgery

\begin{tabular}{l|l} 
Rectal irradiation & $8(23)$
\end{tabular}

Metastatic site irradiation 3 (9)

Primary tumour resection $\quad 35(100)$

Metastatic site resection $\quad 15(43)^{a}$

Liver-directed non-surgical therapy ${ }^{\mathbf{b}} \quad 13(37)^{\mathbf{a}}$

KRAS mutational status

\begin{tabular}{|l|c|}
\hline Wild type & $3(9)$ \\
Mutant $^{\mathrm{c}}$ & $9(26)$ \\
Unknown & $23(66)$
\end{tabular}

Abbreviations: ECOG = Eastern Cooperative Oncology Group; KRAS = kirsten ras gene

${ }^{a}$ Patients for whom multiple procedures of same type performed were counted only once.

${ }^{\mathbf{b}}$ Chemoembolisation $(n=1)$, ablative procedure $(n=8)$, and hepatic arterial infusion $(n=4)$.

${ }^{c}$ For characteristic activating mutations.

dose reduction during DLT window. The DL +1 was subsequently determined to be the MTD and RP2D with one DLT occurring among six evaluable patients.

Six additional patients were enrolled to the planned PK expansion cohort at $\mathrm{DL}+1$. Two of these patients were not evaluable for $\mathrm{PK}$ and were replaced with two additional patients for a total of eight patients in this cohort.

AEs and patient disposition. Table 3 displays treatment-related AE. Overall, treatment-related AE was observed in 34 of 35 (97\%) of patients, with treatment-related grade $\geqslant 3 \mathrm{AE}$ occurring in 11 of 


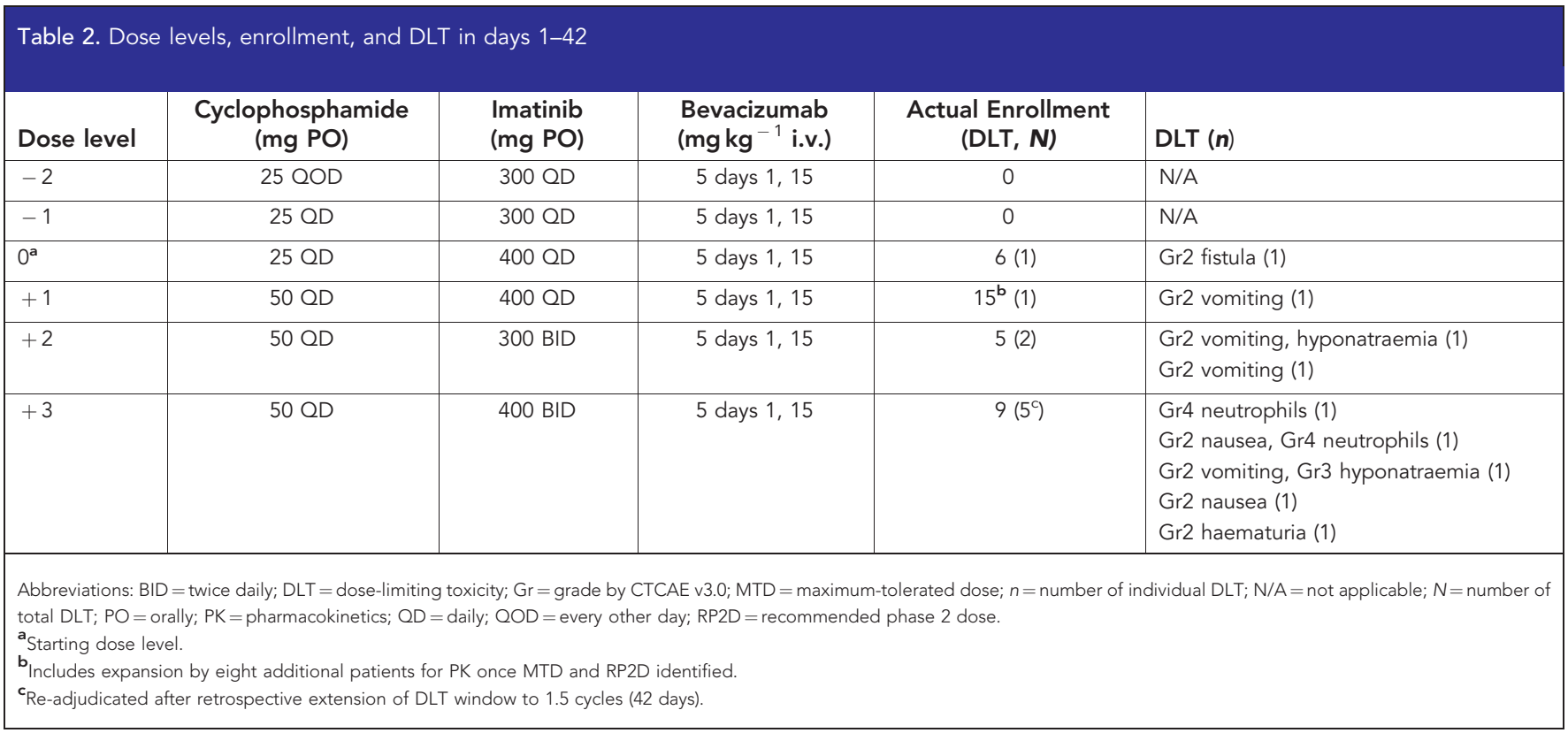

35 patients (31\%). The most common treatment-related AEs (with incidence $\geqslant 20 \%$ in the overall population) were nausea, fatigue, vomiting, diarrhoea, anorexia, rash, neutropaenia, hyperbilirubinaemia, and proteinuria. The majority of symptomatic toxicities were amenable to supportive care including anti-emetic, antidiarrheal, and topical agents. Grade 3 and 4 events assessed as at least possibly treatment related were neutropaenia (11\%), hyperbilirubinaemia (6\%), hypertension (6\%), hyponatraemia (6\%), abdominal pain $(3 \%)$, erythaema multiforme $(3 \%)$, haematuria (3\%), and pulmonary embolism (3\%).

Among the 35 patients enrolled, 33 patients were removed from study upon disease progression: 28 for radiographic progression, 3 for clinical progression, and 2 for death attributed to disease progression on study. Only one patient required treatment discontinuation for toxicity (possibly related grade 2 abdominal fistula resulting in a DLT in DL0, followed by radiographic progression within 1 month later). One grade 5 possibly-related death occurred in $\mathrm{DL}+1$ in a patient who developed intermittent right upper quadrant, flank, and epigastric pain for which protocol therapy was held on C7D1 and not restarted. One week later, he was hospitalised for abdominal pain. The CT imaging was negative for acute obstructive or thrombotic events, so he was discharged after optimisation of pain medications. One week following this, he collapsed after acute abdominal pain and bilious emesis. He was found in cardiopulmonary arrest and expired in transit to hospital. The cause of death was unknown.

Response to therapy and PFS. The best response was unconfirmed stable disease in $15(43 \%)$ and confirmed stable disease in 7 (20\%) of the 35 patients enrolled. The median PFS in the overall study population was 1.88 months (95\% confidence interval: 1.85 , 3.60), with PFS ranging from 1.0 to 14.7 months. In all, 7 (20\%) of the 35 patients had stable disease for at least 6 months. Among these patients, six of seven (86\%) demonstrated evidence of radiographic progression at study entry; the remaining patient had clinical progression. There was no significant difference in PFS or response across DLs (Figure 1).

Pharmacokinetics. Five of six planned patients enrolled at the MTD expansion cohort were evaluable for cyclophosphamide and imatinib pharmacokinetics. One patient was not evaluable due to incomplete collection of PK samples. Imatinib pharmacokinetics are presented in Table 4. Values for imatinib $C_{\max }$ increased between C1D1 and C2D1, as expected based on the drug's long half-life. Exposure values of imatinib and CGP74588 on C1D1 $\left(\mathrm{AUC}_{0 \text {-inf }}\right)$ and $\mathrm{C} 2 \mathrm{D} 1$ ( $\mathrm{UCC}_{0-24 \mathrm{~h}}$ because imatinib is at steady state) appeared to increase, but these effects did not reach statistical significance $(P=0.063)$, as shown in Figures $2 \mathrm{~A}$ and B and Table 4.

The mean cyclophosphamide plasma concentrations at each time point are plotted against time in Supplementary Figure S1. Cyclophosphamide PK parameters were calculated using the plasma concentrations obtained during $24 \mathrm{~h}$ after treatment. Cyclophosphamide treatment at a dose of $50 \mathrm{mg}$ resulted in a $C_{\max }$ of $1234 \pm 162 \mu \mathrm{gl}^{-1}$ at $0.8 \mathrm{~h}$ post dosing. $\mathrm{AUC}_{0 \text {-inf }}$ was $17588 \pm 4929 \mu \mathrm{gl}^{-1} \times \mathrm{h}$ ), the elimination $t_{1 / 2}$ was $10.8 \pm 2.2 \mathrm{~h}$, the $\mathrm{Vd} / \mathrm{F}$ was $0.45 \pm 0.041 \mathrm{~kg}^{-1}$ and the $\mathrm{Cl} / \mathrm{F}$ of the drug was $0.03 \pm 0.01 \mathrm{~h} \mathrm{~h}^{-1} \mathrm{~kg}^{-1}$. The cyclophosphamide PK parameter data are presented in Supplementary Table S1.

CTC and CEC. Circulating tumour cells in $7.5 \mathrm{ml}$ of blood were enumerated using the CellSearch system (Janssen Diagnostics, LLC, Raritan, NJ, USA). At baseline, 47\% (15 out of 32) of patients had unfavourable CTC levels ( $\geqslant 3$ CTC per $7.5 \mathrm{ml}$ of blood) with a median of 1 CTC per $7.5 \mathrm{ml}$ (range 0-118). Circulating tumour cell numbers at baseline and other time points as well as changes in levels of CTCs during treatment did not show statistically significant correlation with time to treatment failure (TTF), PFS, or best response.

The CECs and CEC-related subpopulations were enumerated in $50 \mu \mathrm{l}$ of blood by flow cytometry (Rugo et al, 2012). At baseline, median CEC CD $31+$ and CEC CD146 + were 16.3 cells per $\mu \mathrm{l}$ (range 3.2-44.5) and 1.1 cells per $\mu$ l (range $0.1-10.2$ ), respectively. Baseline median progenitor $(\mathrm{CD} 133+)$ and activated $(\mathrm{CD} 105+)$ CEC were 0.48 cells per $\mu$ l (range $0.02-27.17$ ) and 4.37 cells per $\mu \mathrm{l}$ (range 1.20-27.49), respectively. Absolute levels and change in CEC and CEC subpopulations during treatment did not show any correlation with outcome and response. However, the ratio of CEC subpopulations CD146 +/CD31 + at cycle 1 day 15 showed a significant correlation with TTF $(P=0.0007)$, PFS $(P=0.0002)$, and best response $(P=<0.0001)$.

Immune cells. To assess whether this combination regimen induced any immunomodulatory effects, blood samples obtained every 2 weeks on study were assessed for the frequency and activation status of T-cell and dendritic cell subsets. Two of six assessed patients appeared to have an increase in the frequency of 
Table 3. Treatment-related adverse events by dose level

\begin{tabular}{|c|c|c|c|c|c|c|c|c|c|}
\hline & & \multicolumn{2}{|c|}{ Dose level $0(n=6)$} & \multicolumn{2}{|c|}{ Dose level $+1(n=15)$} & \multicolumn{2}{|c|}{ Dose level $+2(n=5)$} & \multicolumn{2}{|c|}{ Dose level $+3(n=9)$} \\
\hline Body system & Overall All grades & Grade $1 / 2$ & Grade 3/4 & Grade $1 / 2$ & Grade 3/4 & Grade $1 / 2$ & Grade $3 / 4$ & Grade $1 / 2$ & Grade 3/4 \\
\hline \multicolumn{10}{|l|}{ Blood } \\
\hline Haemoglobin & $4(11 \%)$ & $1(17 \%)$ & 0 & $2(13 \%)$ & 0 & 0 & 0 & $1(11 \%)$ & 0 \\
\hline Neutrophils & $8(23 \%)$ & $1(17 \%)$ & 0 & $2(13 \%)$ & 0 & $1(20 \%)$ & $1(20 \%)$ & 0 & $3(33 \%)$ \\
\hline Platelets & $4(11 \%)$ & 0 & 0 & $2(13 \%)$ & 0 & $2(40 \%)$ & 0 & 0 & 0 \\
\hline \multicolumn{10}{|l|}{ Cardiac } \\
\hline Hypertension & $6(17 \%)$ & $2(33 \%)$ & 0 & 0 & $2(13 \%)$ & $1(20 \%)$ & 0 & $1(11 \%)$ & 0 \\
\hline \multicolumn{10}{|l|}{ Constitutional } \\
\hline Fatigue & $23(66 \%)$ & 0 & 0 & $12(80 \%)$ & $1(7 \%)$ & $2(40 \%)$ & 0 & $8(89 \%)$ & 0 \\
\hline Insomnia & 5 (14\%) & 0 & 0 & $4(27 \%)$ & 0 & 0 & 0 & $1(11 \%)$ & 0 \\
\hline Death & $1 *(3 \%)$ & 0 & 0 & 0 & $1^{\mathrm{a}}(7 \%)$ & 0 & 0 & 0 & 0 \\
\hline \multicolumn{10}{|l|}{ Dermatologic } \\
\hline Rash & $8(23 \%)$ & $3(50 \%)$ & 0 & $2(13 \%)$ & 0 & $2(40 \%)$ & 0 & $1(11 \%)$ & 0 \\
\hline Erythaema multiforme & $1(3 \%)$ & 0 & 0 & 0 & $1(7 \%)$ & 0 & 0 & 0 & 0 \\
\hline \multicolumn{10}{|l|}{ Gastrointestinal } \\
\hline Nausea & $26(74 \%)$ & $3(50 \%)$ & 0 & $10(67 \%)$ & 0 & $5(100 \%)$ & 0 & $8(89 \%)$ & 0 \\
\hline Diarrhoea & 12 (34\%) & $2(33 \%)$ & 0 & $6(40 \%)$ & 0 & $1(20 \%)$ & 0 & $3(33 \%)$ & 0 \\
\hline Vomiting & 17 (49\%) & $2(33 \%)$ & 0 & $6(40 \%)$ & 0 & $4(80 \%)$ & 0 & $5(56 \%)$ & 0 \\
\hline Anorexia & 8 (23\%) & 0 & 0 & 7 (47\%) & 0 & 0 & 0 & $1(11 \%)$ & 0 \\
\hline Taste alteration & $4(11 \%)$ & 0 & 0 & 0 & 0 & $1(20 \%)$ & 0 & $3(33 \%)$ & 0 \\
\hline \multicolumn{10}{|l|}{ Lymphatic } \\
\hline Oedema & $5(14 \%)$ & 0 & 0 & $3(20 \%)$ & 0 & 0 & 0 & $2(22 \%)$ & 0 \\
\hline \multicolumn{10}{|l|}{ Metabolic } \\
\hline Proteinuria & $7(20 \%)$ & $1(17 \%)$ & 0 & $5(33 \%)$ & 0 & 0 & 0 & $1(11 \%)$ & 0 \\
\hline Hyperbilirubinaemia & $7(20 \%)$ & 0 & 0 & $5(33 \%)$ & $1(13 \%)$ & 0 & 0 & 0 & $1(11 \%)$ \\
\hline Creatinine increased & $4(11 \%)$ & 0 & 0 & $2(13 \%)$ & 0 & 0 & 0 & $2(22 \%)$ & 0 \\
\hline Alkaline phos incr & $2(6 \%)$ & 0 & 0 & 0 & $1(7 \%)$ & 0 & 0 & $1(11 \%)$ & 0 \\
\hline Hyponatraemia & $2(6 \%)$ & 0 & 0 & 0 & 0 & 0 & 0 & 0 & $2(22 \%)$ \\
\hline \multicolumn{10}{|l|}{ Renal } \\
\hline Haematuria & $1(3 \%)$ & 0 & 0 & 0 & 0 & 0 & & 0 & $1(11 \%)$ \\
\hline \multicolumn{10}{|l|}{ Pain } \\
\hline Abdominal pain & $2(6 \%)$ & 0 & 0 & $1(7 \%)$ & $1(7 \%)$ & 0 & 0 & 0 & 0 \\
\hline \multicolumn{10}{|l|}{ Pulmonary/Vascular } \\
\hline Thrombosis & $1(3 \%)$ & 0 & 0 & 0 & 0 & 0 & 0 & 0 & $1(11 \%)$ \\
\hline
\end{tabular}

FoxP3 + Treg cells, while there were no apparent changes observed in four of six patients (Supplementary Figure S2). There were no consistent changes in other subsets.

\section{DISCUSSION}

To our knowledge, this is the first published clinical trial studying metronomic chemotherapy combined with anti-angiogenic agents in a cohort of patients with refractory metastatic CRC. The results of this phase 1 trial suggest that metronomic oral administration of $50 \mathrm{mg}$ cyclophosphamide daily combined with $400 \mathrm{mg}$ imatinib orally daily and $5 \mathrm{mg} \mathrm{kg}^{-1}$ i.v. bevacizumab every other week has acceptable safety and tolerability in a heavily pre-treated patient population. The most common treatment-related AEs in all patients were nausea, fatigue, vomiting, and diarrhoea; these were manageable with aggressive supportive care. Seven of thirty-five patients (20\%), among whom $86 \%$ had radiographic progression at study enrollment, demonstrated disease stabilisation for at least 6 


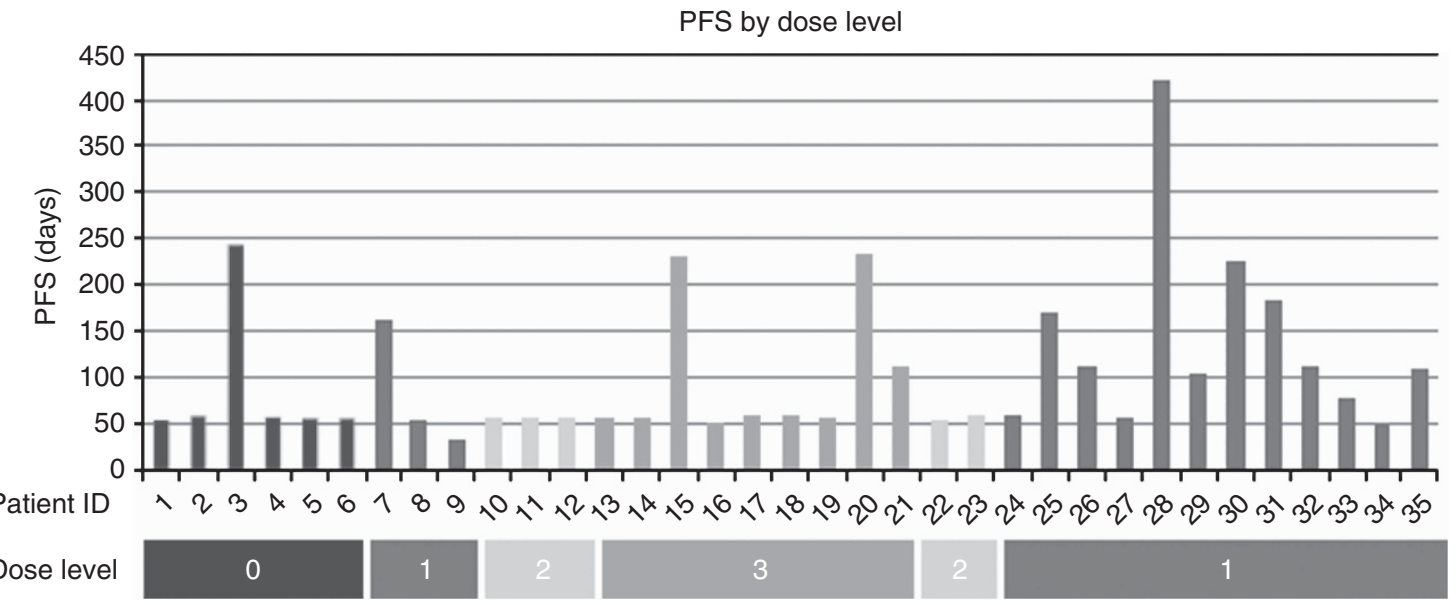

Figure 1. Progression-free survival and dose level. PFS was calculated from the first dose of protocol therapy until date of removal from study for radiographic or clinical progression or death from any cause. Among patients who were removed from study for reasons other than progression or death, PFS was censored at date of last contact or study removal. There was no significant difference in PFS or response across dose levels.

Table 4. Pharmacokinetic parameters of imatinib and CGP74588

\begin{tabular}{|c|c|c|c|c|c|c|c|c|c|c|}
\hline Subject & $\begin{array}{l}\text { Weight } \\
(\mathrm{kg})\end{array}$ & $\begin{array}{l}\text { Dose } \\
\text { (mg) }\end{array}$ & $\begin{array}{c}\text { IMA } \\
C_{\max } \\
\left(\mu \mathrm{g} \mathrm{ml}^{-1}\right) \\
\mathrm{C}_{101}\end{array}$ & $\begin{array}{c}\text { IMA } \\
C_{\max } \\
\left(\mu \mathrm{g} \mathrm{ml}^{-1}\right) \\
\mathrm{C}_{2} \mathrm{D} 1\end{array}$ & $\begin{array}{c}\text { IMA } \\
\text { AUC }_{0-\text { inf }} \\
\left(\mu \mathrm{gh} \mathrm{ml}^{-1}\right) \\
\text { C1D1 }\end{array}$ & $\begin{array}{c}\text { IMA } \\
\mathrm{AUC}_{0-24} \\
\left(\mu \mathrm{gh} \mathrm{m}{ }^{-1} \mathrm{I}\right) \\
\mathrm{C} 2 \mathrm{D} 1\end{array}$ & $\begin{array}{c}\text { CGP } \\
C_{\max } \\
\left(\mu \mathrm{g} \mathrm{ml}^{-1}\right) \\
\mathrm{C}^{-1 D 1}\end{array}$ & $\begin{array}{c}\text { CGP } \\
C_{\max } \\
\left(\mu \mathrm{g} \mathrm{ml}^{-1}\right) \\
\text { C2D1 }^{2}\end{array}$ & $\begin{array}{c}\text { CGP } \\
\text { AUC }_{\text {o-inf }} \\
\left(\mu \mathrm{gh} \mathrm{ml}^{-1}\right) \\
\text { C1D1 }\end{array}$ & $\begin{array}{c}\text { CGP } \\
\text { AUC }_{0-24} \\
\left(\mu \mathrm{g} \mathrm{h} \mathrm{ml}^{-1}\right) \\
\mathrm{C}^{-1} 1\end{array}$ \\
\hline 30 & 131 & 400 & 2.17 & 2.78 & 32.4 & 42.5 & 0.326 & 0.399 & 4.27 & 6.95 \\
\hline 32 & 94 & 400 & 3.56 & 4.50 & 48.1 & 64.9 & 0.387 & 0.663 & 5.32 & 8.14 \\
\hline 33 & 97 & 400 & 4.16 & 5.19 & 64.5 & 82.8 & 0.534 & 0.924 & 8.40 & 17.3 \\
\hline 34 & 89 & 400 & 4.89 & 3.01 & 67.1 & 39.9 & 0.735 & 0.844 & 10.8 & 14.9 \\
\hline 35 & 94 & 400 & 3.31 & 3.87 & 40.3 & 45.4 & 0.372 & 0.732 & 5.52 & 9.71 \\
\hline $\begin{array}{l}\text { Mean } \\
\pm \text { s.d. }\end{array}$ & $\begin{array}{l}101 \\
\pm 17\end{array}$ & 400 & $\begin{array}{c}3.62 \\
\pm 1.01\end{array}$ & $\begin{array}{c}3.87 \\
\pm 1.01\end{array}$ & $\begin{array}{c}50.5 \\
\pm 15.1\end{array}$ & $\begin{array}{l}55.1 \\
\pm 18.4\end{array}$ & $\begin{array}{c}0.471 \\
\pm 0.167\end{array}$ & $\begin{array}{c}0.712 \\
\pm 0.202\end{array}$ & $\begin{array}{r}6.87 \\
+2.69\end{array}$ & $\begin{array}{r}11.4 \\
\pm 4.5\end{array}$ \\
\hline & & & $P$-value & 0.63 & $P$-value & 0.63 & $P$-value & 0.063 & $P$-value & 0.063 \\
\hline
\end{tabular}
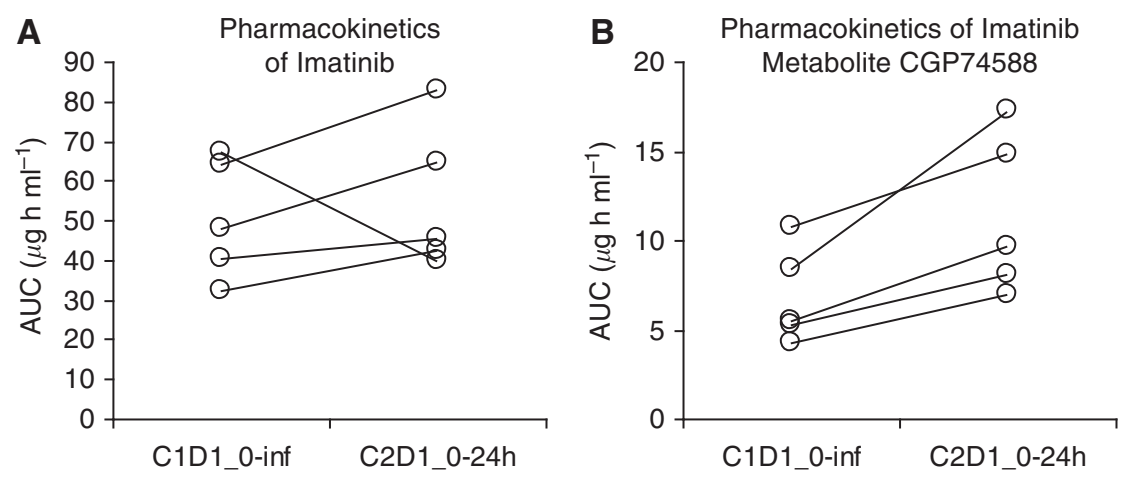

Figure 2. Pharmacokinetics of imatinib and CGP74588. Area under the concentration vs time curve on $\mathrm{C}_{1 \mathrm{D} 1}$ ( $\left(\mathrm{AUC} \mathrm{C}_{0 \text {-inf }}\right)$ and $\mathrm{C}_{2 \mathrm{D} 1}\left(\mathrm{AUC} \mathrm{C}_{0-24 \mathrm{~h}}\right.$ because imatinib is at steady state) was compared for imatinib (A) and its metabolite, CGP74588 (B). Values for imatinib $C_{\text {max }}$ increased between C1D1 and C2D1, as expected based on the drug's long half-life. Exposure values of imatinib and CGP74588 on C1D1 and C2D1 appeared to increase, but these effects did not reach statistical significance $(P=0.063)$. 
months, though there were no radiographic responses by RECIST 1.0 , and the majority of patients progressed within 2 months.

Although the prolonged disease stability observed in $20 \%$ is intriguing, the findings in our study provide an inadequate signal to justify further study in the absence of predictive biomarkers and/ or a more complete understanding of mechanisms underlying the potential anti-tumour efficacy. In this phase 1, single arm study, the true anti-tumour activity of the regimen or its individual components is impossible to gauge. Results from the TML trial are relevant, as they suggest that bevacizumab itself has activity post progression and raise the possibility that the events of disease stabilisation observed in our study could be due to effects of bevacizumab alone (Grothey et al, 2008; Bennouna et al, 2013). Whether cyclophosphamide is the optimal cytotoxic agent for metronomic dosing in CRC remains not known (recognising that tumour-associated endothelial cells are at least one target). Furthermore, other PDGFR $\beta$ inhibitors have been developed since the inception of this study, including regorafenib (whose targets include VEGFR1, VEGFR2, VEGFR3, PDGFR $\beta$, Kit, RET, and Raf-1), which is now approved for refractory CRC and has a distinct, but overlapping profile of target inhibition compared with imatinib (Grothey et al, 2013). Nonetheless, the safety data and pharmacokinetics in this novel study may inform future metronomic and combination therapy approaches.

This study exemplifies the challenges of toxicity and tolerability assessment and attribution in multi-drug targeted therapy regimens. An important observation is that intolerability due to a constellation of grade 1 and 2 AEs occurred in a significant proportion of patients, resulting in delays and dose reductions soon after completion of the standard 28-day (1 cycle) DLT window. In response to this finding, the DLT window was expanded to 42 days (1.5 cycles), leading to identification of significantly more toxicity than initially appreciated and requiring de-escalation from $\mathrm{DL}+3$ to $\mathrm{DL}+1$, the eventual MTD regimen (and RP2D). Similar to our experience, Postel-Vinay et al (2011) recently described the toxicity among 445 patients treated with molecularly targeted agents on phase 1 trials at the Royal Marsden Hospital and Institut Gustave Roussy between January 2005 and July 2008. The authors found that $57 \%$ of grade 3 and 4 treatment-related toxicities occurred after cycle 1 of therapy and concluded that toxicities from targeted therapies regularly occur beyond the traditional DLT window and may be important in determining the RP2D (Postel-Vinay et al, 2011).

Another important question raised is how to determine the optimal biologic dose of combination targeted therapy regimens, since the MTD identified by the standard model of dose escalation may not be equivalent to the optimal biologic dose for every drug or combination (Parulekar and Eisenhauer, 2004; Sleijfer and Wiemer, 2008; Postel-Vinay et al, 2011). On-treatment biopsies to test for target engagement or other pharmacodynamic markers are desirable but not uniformly feasible across studies, particularly in the setting of combination regimens for which a validated measure of the complex interplay of multiple agents may not be available. In this study, DCE-CT imaging was undertaken in a small subset of patients to examine the hepatic tumour perfusion as a measure of anti-angiogenic activity (Flaherty et al, 2008; Hahn et al, 2008; Raatschen et al, 2009; Kummar et al, 2011; Ren et al, 2012). Among the patients who underwent serial DCE-CT on this study, no informative changes were observed in tumour blood volume, $K_{\text {trans, }}$, permeability surface, mean transit time, or blood flow, though interpretation of these results is limited by the small sample size and the modest therapeutic efficacy (data not shown).

Imatinib C1D1 $\mathrm{AUC}_{0 \text {-inf }}$ and $\mathrm{C} 2 \mathrm{D} 1 \mathrm{AUC}_{0-24 \mathrm{~h}}$ values observed were in the range of $30-80 \mu \mathrm{g} \mathrm{h} \mathrm{ml}^{-1}$, which agrees with exposures at doses of 400-600 mg reported in the literature (Peng et al, 2005). The increase in imatinib $C_{\max }$ over serial time points could be explained by the expected accumulation index based on the imatinib half-life and the dose interval. The increases in imatinib and CGP74588 AUC over serial time points suggest that addition of bevacizumab and cyclophosphamide reduces imatinib clearance. However, these effects did not reach statistical significance in this small sample. Human CYP3A4 is involved in the metabolism of cyclophosphamide, and could possibly be a competitive inhibitor to imatinib metabolism (Bohnenstengel et al, 1996). On the other hand, cyclophosphamide has been reported to induce CYP3A4 metabolism in human liver slices, potentially leading to increased imatinib metabolism (Martin et al, 2003). The net effect in this trial could be inhibition of imatinib metabolism, and this is supported by a murine study showing a $41 \%$ reduction in CYP3A4 activity after 8 weeks of cyclophosphamide treatment (Emmenegger et al, 2007).

Pharmacokinetic analyses showed that the exposure to $50 \mathrm{mg}$ daily metronomic dosing of cyclophosphamide, measured on cycle 2 , day 1 with imatinib at steady state, was consistent with previous single dose cyclophosphamide PK data for adult non-Hodgkin's lymphoma and for paediatric recurrent solid tumours, suggesting against a significant interaction with imatinib (Stempak et al, 2006). Technical difficulties precluded measurement of 4-hydroperoxycyclophosphamide (4-OHCP) levels, the major active (cytotoxic) microsomal metabolite of cyclophosphamide.

Levels of CTCs (at baseline and changes on therapy) were not associated with PFS or response in the study population. Though multiple other studies and meta-analysis data have established CTC as a poor prognostic factor and potential predictive marker of early response, the majority of these studies examined patients earlier in their disease history, particularly first-line metastatic CRC (Cohen et al, 2009; Rahbari et al, 2010; Tol et al, 2010). We surmise that the heavily pretreated patient population, modest treatment efficacy, and small sample size may have obscured our ability to detect any meaningful relationship in our study. The significance of the association between the absolute number of CD146-positive CECs on cycle 1, day 15 and outcome is unclear, owing to the small sample size and the absence of any trend at other time points (noting that a Bonferroni correction was not performed).

While both metronomic cyclophosphamide and VEGF-targeted therapy as single-agent treatments have been shown to enhance anti-tumour immunity by reducing the frequency of Tregs or enhancing dendritic cell activation ( $\mathrm{Li}$ et al, 2006), our study combining these approaches showed no apparent increase in effector T cells, while Tregs appeared to increase on therapy in two of the six patients assessed. Though interpretation is limited by small sample size, this finding is reminiscent of a recent report showing an unexpected decrease in innate immune cell recruitment and decreased tumour regression when VEGF receptor inhibition was added to metronomic cyclophosphamide in a mouse model of brain tumours (Doloff and Waxman, 2012). These results highlight the need for valid preclinical models and the importance of integrating pharmacodynamic studies when undertaking novel combinations in clinical trials.

The combination regimen of metronomic cyclophosphamide, imatinib, and bevacizumab in heavily pretreated patients with refractory metastatic CRC appears to be safe. Successful development of this therapeutic strategy would require randomised trials designed to determine the incremental benefit of each individual component, ideally compared with a best supportive care arm in the treatment-refractory setting. Given the refractory nature of this patient population and the anticipated modest benefit in the group as a whole, predictive biomarkers and improved tools to detect response would significantly improve the ability to discern and define benefit. Our data suggest that a standard 28-day DLT window may not adequately capture tolerability of a metronomic regimen, and that the activity of metronomic regimens may be best measured by time-to-event end points such as PFS or time to progression rather than response rate. Furthermore, while toxicity 
appears to be dose dependent, our data show no clear relationship between dose and efficacy. Predictive biomarkers along with pharmacodynamic markers of target engagement are needed to understand the mechanisms of action, discern optimal biologic dose, and identify the patients most likely to respond to a metronomic approach, and to anti-angiogenic therapies in general. The limited success to date to identify consistent predictive biomarkers of response to bevacizumab across tumour types underscores the complexity of angiogenesis and the tumour microenvironment as therapeutic targets.

\section{ACKNOWLEDGEMENTS}

We would like to express our deep appreciation of the many patients with advanced CRCs who participated in this clinical trial, along with their families, for their dedication and donation to medical oncology research. We also would like to share our sincere gratitude to the late Merrill J Egorin for his contributions to the imatinib pharmacokinetic analyses in this paper, as well as for his far-reaching dedication to medical oncology research and education. Imatinib and funding for this study were supplied by Novartis. RKK was supported in part by the Maisin Foundation. This project used the UPCI Clinical Pharmacology Analytical Facility (CPAF) and was supported in part by award P30CA047904 (JHB). Mass Spectrometry Analysis for cyclophosphamide pharmacokinetic samples was performed at the Analytical Facility for Bioactive Molecules (AFBM) by Michael Leadley. The AFBM is part of the Centre for the Study of Complex Childhood Diseases (CSCCD) at the Hospital for Sick Children, Toronto, Ontario. CSCCD was supported by the Canadian Foundation for Innovation (CFI). EKB was supported in part by a grant from the $\mathrm{V}$ Foundation.

\section{CONFLICT OF INTEREST}

EKB and APV have received research support from Novartis and Genentech. JHB has received research support from Novartis.

\section{REFERENCES}

Allard WJ, Matera J, Miller MC, Repollet M, Connelly MC, Rao C, Tibbe AG, Uhr JW, Terstappen LW (2004) Tumor cells circulate in the peripheral blood of all major carcinomas but not in healthy subjects or patients with nonmalignant diseases. Clin Cancer Res 10: 6897-6904.

Allegrini G, Falcone A, Fioravanti A, Barletta MT, Orlandi P, Loupakis F, Cerri E, Masi G, Di Paolo A, Kerbel RS, Danesi R, Del Tacca M, Bocci G (2008) A pharmacokinetic and pharmacodynamic study on metronomic irinotecan in metastatic colorectal cancer patients. Br J Cancer 98: 1312-1319.

Bennouna J, Sastre J, Arnold D, Osterlund P, Greil R, Van Cutsem E, Von Moos R, Vieitez JM, Bouche O, Borg C, Steffens CC, Alonso-Orduna V, Schlichting C, Reyes-Rivera I, Bendahmane B, Andre T, Kubicka S. ML18147 Study Investigators (2013) Continuation of bevacizumab after first progression in metastatic colorectal cancer (ML18147): a randomised phase 3 trial. Lancet Oncol 14: 29-37.

Bertolini F, Paul S, Mancuso P, Monestiroli S, Gobbi A, Shaked Y, Kerbel RS (2003) Maximum tolerable dose and low-dose metronomic chemotherapy have opposite effects on the mobilization and viability of circulating endothelial progenitor cells. Cancer Res 63: 4342-4346.

Blansfield JA, Caragacianu D, Alexander 3rd HR, Tangrea MA, Morita SY, Lorang D, Schafer P, Muller G, Stirling D, Royal RE, Libutti SK (2008) Combining agents that target the tumor microenvironment improves the efficacy of anticancer therapy. Clin Cancer Res 14: 270-280.

Bocci G, Nicolaou KC, Kerbel RS (2002) Protracted low-dose effects on human endothelial cell proliferation and survival in vitro reveal a selective antiangiogenic window for various chemotherapeutic drugs. Cancer Res 62: 6938-6943.

Bohnenstengel F, Hofmann U, Eichelbaum M, Kroemer HK (1996) Characterization of the cytochrome P450 involved in side-chain oxidation of cyclophosphamide in humans. Eur J Clin Pharmacol 51: 297-301.

Browder T, Butterfield CE, Kraling BM, Shi B, Marshall B, O’reilly MS, Folkman J (2000) Antiangiogenic scheduling of chemotherapy improves efficacy against experimental drug-resistant cancer. Cancer Res 60: 1878-1886.

Cohen SJ, Punt CJ, Iannotti N, Saidman BH, Sabbath KD, Gabrail NY, Picus J, Morse M, Mitchell E, Miller MC, Doyle GV, Tissing H, Terstappen LW, Meropol NJ (2008) Relationship of circulating tumor cells to tumor response, progression-free survival, and overall survival in patients with metastatic colorectal cancer. J Clin Oncol 26: 3213-3221.

Cohen SJ, Punt CJ, Iannotti N, Saidman BH, Sabbath KD, Gabrail NY, Picus J, Morse MA, Mitchell E, Miller MC, Doyle GV, Tissing H, Terstappen LW, Meropol NJ (2009) Prognostic significance of circulating tumor cells in patients with metastatic colorectal cancer. Ann Oncol 20: 1223-1229.

Dellapasqua S, Bertolini F, Bagnardi V, Campagnoli E, Scarano E, Torrisi R, Shaked Y, Mancuso P, Goldhirsch A, Rocca A, Pietri E, Colleoni M (2008) Metronomic cyclophosphamide and capecitabine combined with bevacizumab in advanced breast cancer. J Clin Oncol 26: 4899-4905.

Doloff JC, Waxman DJ (2012) VEGF receptor inhibitors block the ability of metronomically dosed cyclophosphamide to activate innate immunityinduced tumor regression. Cancer Res 72: 1103-1115.

Emmenegger U, Man S, Shaked Y, Francia G, Wong JW, Hicklin DJ, Kerbel RS (2004) A comparative analysis of low-dose metronomic cyclophosphamide reveals absent or low-grade toxicity on tissues highly sensitive to the toxic effects of maximum tolerated dose regimens. Cancer Res 64: 3994-4000.

Emmenegger U, Shaked Y, Man S, Bocci G, Spasojevic I, Francia G, Kouri A, Coke R, Cruz-Munoz W, Ludeman SM, Colvin OM, Kerbel RS (2007) Pharmacodynamic and pharmacokinetic study of chronic low-dose metronomic cyclophosphamide therapy in mice. Mol Cancer Ther 6: 2280-2289.

Flaherty KT, Rosen MA, Heitjan DF, Gallagher ML, Schwartz B, Schnall MD, O'dwyer PJ (2008) Pilot study of DCE-MRI to predict progression-free survival with sorafenib therapy in renal cell carcinoma. Cancer Biol Ther 7: 496-501.

Folkman J (1971) Tumor angiogenesis: therapeutic implications. N Engl J Med 285: 1182-1186.

Garcia AA, Hirte H, Fleming G, Yang D, Tsao-Wei DD, Roman L, Groshen S, Swenson S, Markland F, Gandara D, Scudder S, Morgan R, Chen H, Lenz HJ, Oza AM (2008) Phase II clinical trial of bevacizumab and low-dose metronomic oral cyclophosphamide in recurrent ovarian cancer: a trial of the California, Chicago, and Princess Margaret Hospital phase II consortia. J Clin Oncol 26: 76-82.

Garcia JA, Rosenberg JE, Weinberg V, Scott J, Frohlich M, Park JW, Small EJ (2007) Evaluation and significance of circulating epithelial cells in patients with hormone-refractory prostate cancer. BJU Int 99: 519-524.

Ge Y, Domschke C, Stoiber N, Schott S, Heil J, Rom J, Blumenstein M, Thum J, Sohn C, Schneeweiss A, Beckhove P, Schuetz F (2012) Metronomic cyclophosphamide treatment in metastasized breast cancer patients: immunological effects and clinical outcome. Cancer Immunol Immunother 61: 353-362.

Ghiringhelli F, Menard C, Puig PE, Ladoire S, Roux S, Martin F, Solary E, Le Cesne A, Zitvogel L, Chauffert B (2007) Metronomic cyclophosphamide regimen selectively depletes $\mathrm{CD} 4+\mathrm{CD} 25+$ regulatory $\mathrm{T}$ cells and restores $\mathrm{T}$ and NK effector functions in end stage cancer patients. Cancer Immunol Immunother 56: 641-648.

Grothey A, Sugrue MM, Purdie DM, Dong W, Sargent D, Hedrick E, Kozloff M (2008) Bevacizumab beyond first progression is associated with prolonged overall survival in metastatic colorectal cancer: results from a large observational cohort study (BRiTE). J Clin Oncol 26: 5326-5334.

Grothey A, Van Cutsem E, Sobrero A, Siena S, Falcone A, Ychou M, Humblet Y, Bouche O, Mineur L, Barone C, Adenis A, Tabernero J, Yoshino T, Lenz HJ, Goldberg RM, Sargent DJ, Cihon F, Cupit L, Wagner A, Laurent D, Group CS (2013) Regorafenib monotherapy for previously treated metastatic colorectal cancer (CORRECT): an international, multicentre, randomised, placebo-controlled, phase 3 trial. Lancet 381: 303-312.

Hahn OM, Yang C, Medved M, Karczmar G, Kistner E, Karrison T, Manchen E, Mitchell M, Ratain MJ, Stadler WM (2008) Dynamic contrast-enhanced 
magnetic resonance imaging pharmacodynamic biomarker study of sorafenib in metastatic renal carcinoma. J Clin Oncol 26: 4572-4578.

Hurwitz H, Fehrenbacher L, Novotny W, Cartwright T, Hainsworth J, Heim W, Berlin J, Baron A, Griffing S, Holmgren E, Ferrara N, Fyfe G, Rogers B, Ross R, Kabbinavar F (2004) Bevacizumab plus irinotecan, fluorouracil, and leucovorin for metastatic colorectal cancer. $N$ Engl J Med 350: $2335-2342$.

Jemal A, Siegel R, Xu J, Ward E (2010) Cancer statistics, 2010. CA Cancer J Clin 60: 277-300.

Kerbel RS, Kamen BA (2004) The anti-angiogenic basis of metronomic chemotherapy. Nat Rev Cancer 4: 423-436.

Kummar S, Gutierrez ME, Chen A, Turkbey IB, Allen D, Horneffer YR, Juwara L, Cao L, Yu Y, Kim YS, Trepel J, Chen H, Choyke P, Melillo G, Murgo AJ, Collins J, Doroshow JH (2011) Phase I trial of vandetanib and bevacizumab evaluating the VEGF and EGF signal transduction pathways in adults with solid tumours and lymphomas. Eur J Cancer 47: 997-1005.

Li B, Lalani AS, Harding TC, Luan B, Koprivnikar K, Huan TuG, Prell R, Vanroey MJ, Simmons AD, Jooss K (2006) Vascular endothelial growth factor blockade reduces intratumoral regulatory $\mathrm{T}$ cells and enhances the efficacy of a GM-CSF-secreting cancer immunotherapy. Clin Cancer Res 12: $6808-6816$

Martin H, Sarsat JP, De Waziers I, Housset C, Balladur P, Beaune P, Albaladejo V, Lerche-Langrand C (2003) Induction of cytochrome P450 $2 \mathrm{~B} 6$ and 3A4 expression by phenobarbital and cyclophosphamide in cultured human liver slices. Pharm Res 20: 557-568.

Motoyoshi Y, Kaminoda K, Saitoh O, Hamasaki K, Nakao K, Ishii N, Nagayama Y, Eguchi K (2006) Different mechanisms for anti-tumor effects of low- and high-dose cyclophosphamide. Oncol Rep 16: 141-146.

Parise RA, Ramanathan RK, Hayes MJ, Egorin MJ (2003) Liquid chromatographic-mass spectrometric assay for quantitation of imatinib and its main metabolite (CGP 74588) in plasma. J Chromatogr B Analyt Technol Biomed Life Sci 791: 39-44.

Parulekar WR, Eisenhauer EA (2004) Phase I trial design for solid tumor studies of targeted, non-cytotoxic agents: theory and practice. J Natl Cancer Inst 96: 990-997.

Penel N, Adenis A, Bocci G (2011) Cyclophosphamide-based metronomic chemotherapy: After 10 years of experience, where do we stand and where are we going? Crit Rev Oncol Hematol 82: 40-50.

Peng B, Lloyd P, Schran H (2005) Clinical pharmacokinetics of imatinib. Clin Pharmacokinet 44: 879-894.

Pietras K, Hanahan D (2005) A multitargeted, metronomic, and maximumtolerated dose 'chemo-switch' regimen is antiangiogenic, producing objective responses and survival benefit in a mouse model of cancer. J Clin Oncol 23: 939-952.

Postel-Vinay S, Gomez-Roca C, Molife LR, Anghan B, Levy A, Judson I, De Bono J, Soria JC, Kaye S, Paoletti X (2011) Phase I trials of molecularly targeted agents: should we pay more attention to late toxicities? J Clin Oncol 29: 1728-1735.

Raatschen HJ, Fu Y, Brasch RC, Pietsch H, Shames DM, Yeh BM (2009) In vivo monitoring of angiogenesis inhibitory treatment effects by dynamic contrast-enhanced computed tomography in a xenograft tumor model. Invest Radiol 44: 265-270.

Rahbari NN, Aigner M, Thorlund K, Mollberg N, Motschall E, Jensen K, Diener MK, Buchler MW, Koch M, Weitz J (2010) Meta-analysis shows that detection of circulating tumor cells indicates poor prognosis in patients with colorectal cancer. Gastroenterology 138: 1714-1726.

Ren Y, Fleischmann D, Foygel K, Molvin L, Lutz AM, Koong AC, Jeffrey RB, Tian L, Willmann JK (2012) Antiangiogenic and radiation therapy: early effects on in vivo computed tomography perfusion parameters in human colon cancer xenografts in mice. Invest Radiol 47: 25-32.

Rugo HS, Chien AJ, Franco SX, Stopeck AT, Glencer A, Lahiri S, Arbushites MC, Scott J, Park JW, Hudis C, Nulsen B, Dickler MN (2012) A phase II study of lapatinib and bevacizumab as treatment for HER2-overexpressing metastatic breast cancer. Breast Cancer Res Treat 134: 13-20.

Sanchez-Munoz A, Mendiola C, Perez-Ruiz E, Rodriguez-Sanchez CA, Jurado JM, Alonso-Carrion L, Ghanem I, De Velasco G, Quero-Blanco C, Alba E (2010) Bevacizumab plus low-dose metronomic oral cyclophosphamide in heavily pretreated patients with recurrent ovarian cancer. Oncology 79: 98-104.

Sleijfer S, Wiemer E (2008) Dose selection in phase I studies: why we should always go for the top. J Clin Oncol 26: 1576-1578.

Stempak D, Gammon J, Halton J, Moghrabi A, Koren G, Baruchel S (2006) A pilot pharmacokinetic and antiangiogenic biomarker study of celecoxib and low-dose metronomic vinblastine or cyclophosphamide in pediatric recurrent solid tumors. J Pediatr Hematol Oncol 28: 720-728.

Talpaz M, Silver RT, Druker BJ, Goldman JM, Gambacorti-Passerini C, Guilhot F, Schiffer CA, Fischer T, Deininger MW, Lennard AL, Hochhaus A, Ottmann OG, Gratwohl A, Baccarani M, Stone R, Tura S, Mahon FX, Fernandes-Reese S, Gathmann I, Capdeville R, Kantarjian HM, Sawyers CL (2002) Imatinib induces durable hematologic and cytogenetic responses in patients with accelerated phase chronic myeloid leukemia: results of a phase 2 study. Blood 99: 1928-1937.

Therasse P, Arbuck SG, Eisenhauer EA, Wanders J, Kaplan RS, Rubinstein L, Verweij J, Van Glabbeke M, Van Oosterom AT, Christian MC, Gwyther SG (2000) New guidelines to evaluate the response to treatment in solid tumors. European Organization for Research and Treatment of Cancer, National Cancer Institute of the United States, National Cancer Institute of Canada. J Natl Cancer Inst 92: 205-216.

Tol J, Koopman M, Miller MC, Tibbe A, Cats A, Creemers GJ, Vos AH, Nagtegaal ID, Terstappen LW, Punt CJ (2010) Circulating tumour cells early predict progression-free and overall survival in advanced colorectal cancer patients treated with chemotherapy and targeted agents. Ann Oncol 21: 1006-1012.

Van Cutsem E, Tabernero J, Lakomy R, Prenen H, Prausová J, Macarulla T, Ruff P, van Hazel GA, Moiseyenko V, Ferry D, McKendrick J, Polikoff J, Tellier A, Castan R, Allegra C (2012) Addition of Aflibercept to Fluorouracil, Leucovorin, and Irinotecan Improves Survival in a Phase III Randomized Trial in Patients With Metastatic Colorectal Cancer Previously Treated With an Oxaliplatin-Based Regimen. J Clin Oncol 30 3499-3506.

Verweij J, Casali PG, Zalcberg J, Lecesne A, Reichardt P, Blay JY, Issels R, Van Oosterom A, Hogendoorn PC, Van Glabbeke M, Bertulli R, Judson I (2004) Progression-free survival in gastrointestinal stromal tumours with high-dose imatinib: randomised trial. Lancet 364: $1127-1134$.

Zalcberg JR, Verweij J, Casali PG, Le Cesne A, Reichardt P, Blay JY, Schlemmer M, Van Glabbeke M, Brown M, Judson IR (2005) Outcome of patients with advanced gastro-intestinal stromal tumours crossing over to a daily imatinib dose of $800 \mathrm{mg}$ after progression on $400 \mathrm{mg}$. Eur J Cancer 41: 1751-1757.

This work is published under the standard license to publish agreement. After 12 months the work will become freely available and the license terms will switch to a Creative Commons AttributionNonCommercial-Share Alike 3.0 Unported License.

Supplementary Information accompanies this paper on British Journal of Cancer website (http://www.nature.com/bjc) 